\title{
Cultural Challenges in Information Systems Innovation: The Need for Differentiation Studies
}

\author{
Carl Lawrence and Markku Oivo \\ Department of Information Processing Science, University of Oulu, \\ P.O. Box 3000, Oulu 90014, Finland
}

\begin{abstract}
Information technology (IT) innovations have been vital to the success of organizations seeking to improve efficiency and productivity. IT's global diffusion has however raised serious questions about its neutral application across cultures and contexts. This paper synthesizes a sample of the literature to conceptualize the key cultural challenges in IS innovation as, differentiation, externality, compatibility, embeddeness. The study shows that the adoption decision is challenged by differentiation, and the adoption phase exhibits issues of externality. During implementation, compatibility is the key challenge of innovators and the assimilation literature revealed that embeddeness was the cultural challenge that phase. The synthesis also revealed that the comprehension phase where adoption decisions are made was lacking significant study. The paper proposes two opportunities for research and examples of research methods that can be use to investigate pre-adoption phenomena.
\end{abstract}

Keywords: Innovation, culture, differentiation, comprehension, methods.

\section{Introduction}

Information technology (IT) is a significant investment for any organization, thus extracting the most value from these innovations is vital, and can be highly rewarding (Rau \& Bye, 2003). As a key resource for business in a new competitive age, IT innovations enable the complex interactions that are required to support our global economy (M. Barrett, Jarvenpaa, Silva, \& Walsham, 2003). IT has become a symbol of progress throughout the world, driving greater global interactions. Information systems (IS) researchers view mitigating the challenges of innovating with IT as imperative to participating in, and reaping the benefits of our new globally connected economy (Mustonen-Ollila \& Lyytinen, 2004).

Many organizations do not possess the technical expertise to develop new IT innovations, thus they are more likely to adopt them. Thus, IS innovation is the adoption of IT innovations for use in unique ways and the term has normally been restricted to early adopters (B. Swanson, 1994; E. B. Swanson, 2010). While many studies have focused on adoption, it is not the initiation of the innovation process. Prior to adoption, the adoption decision must be made, and after adoption, the innovation needs to be implemented, and assimilated by the organization. The benefits of innovation adoption can only truly be realized when it has been integrated into the activities of the organization's value chain (Armstrong \& Sambamurthy, 1999). 
The importance of IT in our global society should not allow for the naive assumptions that innovations will exhibit the same productive attributes in organizations and individuals existing in culturally distant contexts (Ein-Dor, Segev, \& Orgad, 1993; Kaye \& Little, 1996; Vodanovich, Sundaram, \& Myers, 2010; Wagner \& Newell, 2004). Globalization has generated significant research interest in culture and IS, as organizations, seeking to keep pace with a growing competitive marketplace, are motived to adopt the latest innovations at a more rapid rate, ignoring potential pitfalls (M. Barrett et al., 2003; Hanseth \& Braa, 2000; Leidner, 2010). Adoption and the resulting diffusion of IT innovations can adversely affect an organization's culture, often leading to reduced productivity (Vasst \& Walsham, 2005). The dynamic, transformative, and sometimes unpredictable nature of culture presents many challenges to IS innovation, as it is seen as a key mediating factor (L. Harvey \& M.D. Myers, 1995).

It has thus become increasingly important for researchers to address cultural challenges facing organizations when innovating with IT, in order to provide understanding and solutions. Our research question in this paper is thus, what are the cultural challenges facing organizations when they are innovating with IT? To answer this question this paper draws on the rich literary stream on IS innovation and culture. Using Swanson and Ramiller's (2004) IS innovation process framework, the paper extracts and synthesizing a sample of this literature and conceptualizes four challenges -differentiation, externality, incompatibility, and embeddedness. The lack of research investigating comprehension motivated the provision of opportunities for research in this area.

The paper proceeds by providing a brief background on the research on IS innovation and culture, where the IS innovation process and cultural conceptualizations are exposed. Next, a sample of the extant literature on culture and IS innovation is synthesized to identify the challenges. This is followed by a theoretical discussion on the differentiation challenge and opportunities for future research.

\section{Culture and IS Innovation}

The terms "IT and IS innovation" and "IT and IS innovations" are concepts that are intrinsically intertwined and are used liberally throughout the IS discipline. In this paper, the distinction is made based on coverage. The selected term "IS innovation," was introduced and defined by Swanson (1994) as "innovation in the organizational application of digital computer and communications technologies," more commonly known as IT. Other studies have used IT innovation to describe a similar process (King et al., 1994; Wang \& Ramiller, 2009). The selected term "IT innovations" thus refers to both technical, process, and product innovations ${ }^{1}$ (Fichman, 2004; B. Swanson, 1994). Enterprise resource planning (ERP), Microsoft Office, and Agile methodology would all be considered as examples of IT innovations. Henceforth, the terms "IS innovation" and "IT innovations" are used where appropriate. Consequently, IS

\footnotetext{
${ }^{1}$ Swanson (2004) provides a typology of six types of IT innovations.
} 
innovation research is fundamentally concerned with "understanding the factors that facilitate or inhibit the adoption and diffusion of emerging IT-based processes or products within a population of potential adopters" (Fichman, 2004).

Culture has emerged as a cardinal research stream in IS, which can be attributed to the phenomenon of globalization. Barrett et al. (2003) describe globalization as a "process of social change, with many manifestations and connected to issues of self identity," "traditional ways of life affected by common cultural goods and global markets having common techniques of discipline," and "interdependence and diversity in economic, political and social environments". As the catalyst for the growth in cultural studies in IS, globalization has forced re-conceptualizations of culture and IT innovations. The impact has been an increase in studies challenging previously held assumptions regarding technology adoption and diffusion.

Much of the research on IS innovation has been focused on adoption and implementation. Since the 1980s, adoption, and implementation studies have been a mainstay in IS research. While re-conceptualization of these studies into a IS innovation framework did not occur until the early 1990s, there was an assumption that these studies were part of a larger process (Lucas, Swanson, \& Zmud, 2007; B. Swanson, 1994). Empirical research on multiple phases of the IS innovation process requires significant time and resources. Longitudinal studies were typically required to cover all phases of the innovation process. While there have been some that have investigated multiple phases (Kim \& Malhotra, 2005; MustonenOllila \& Lyytinen, 2004; Wagner \& Newell, 2004), generally, studies have only tackled one or two phases. However, what the research stream does not provide is a clear picture of culture's mediating effect on IS innovation and its individual phases.

The attention to culture in this research stream emerged from the social constructionist viewpoint, which situates IT innovations in the context of their design and development (Kaptelinin \& Nardi, 2006; Pinch, 2008; Pinch \& Bijker, 1984) and thus users of IT will view the same IT innovation in different ways (Orlikowski \& Gash, 1994). The focus on cultural research here is due to increased interaction between cultures due to globalization. According to Walsham (2002), culture diversity in itself is not a problem in cultural interaction. It is only when this diversity produces conflict that cultural diversity is cast in a negative light.

While Walsham's (2002) conceptualization of culture as "shared symbols, norms and values in a social collective" is a sufficient definition ${ }^{2}$, by adding the underlying philosophical perspective, a deeper understanding is given to this very complex phenomenon. Moving beyond definitions, culture can be seen as conceptualized based on perspective. In IS research, the positivist paradigm has dominated early research that has given way to a healthy dose of interpretivism. Thus, have conceptualizations of culture moved beyond static characteristics to theories of emergence, construction, and evolution? Previously, IS studies on culture drew

\footnotetext{
${ }^{2}$ This is not a reflection of the perspective of Walsham, an influential figure in IS research on culture.
} 
on Hofstede's dimensions of national culture (Hofstede, 2004). The major critics of Hofstede's cultural dimensions state that they do not take into consideration the complexity of culture in our modern world, nor do they provide explanations for creation, recreation, emergence, or destruction (Myers \& Tan, 2003). The complexity of culture often leads to the avoidance of detail definitions and conceptualizations of culture also leading to an unclear picture of the cultural challenges facing organizations innovating with IT.

\section{Cultural Challenges in IS Innovation}

The framework for the literature review is based on the IS innovation process in organizations, defined by Swanson and Ramiller (2004). This includes the phases, comprehension, adoption, implementation, and assimilation. For synthesis, the sample publications need to provide a range of studies with a tight focus. The articles had to conform to the following criteria: (1) all articles chosen had to be empirical studies; (2) they had to study IS innovation in one or more organizations; (3) they had to develop a descriptive, explanatory, or predictive theory; and (4) they had to specifically implicate culture as having an impact on IS innovation. A literature search of the listed journals from 1999 to 2011 found 27 articles matching these criteria. The literature was first organized by situating each study in one of the four innovation process areas. It became apparent that studies on cultural in the comprehension phase were lacking in our sample, thus additional searching was carried out and theoretical support was added to conceptualize the cultural challenge. Table 1 displays the articles on each theme, and the major points.

\subsection{Differentiation}

The decision to adopt an innovation can be viewed as "a temporal sequence of steps through which an individual passes from initial knowledge of an innovation to forming a favorable or unfavorable attitude toward it, to a decision to adopt or reject it, to putting the innovation to use, and to finally seeking reinforcement of the adoption decision made" (Karahanna, Straub, \& Chervany, 1999). During this process, conceptualized by Swanson (2004) as comprehension, potential adopters seek knowledge and attempt to make sense of IT innovations by accessing the discourses of the IT community. Fastidiousness in this phase varies and typically is reduced to a "me too" approach. Bandwagon phenomena in IS innovation has inspired research that has questioned this "mindless" innovative behavior. Riding the technology bandwagon suggests that an organization adopts a "follow the leader" strategy that exhibits limited reasoning when selecting technologies for adoption (E. B. Swanson \& Ramiller, 2004). While this strategy may prove successful for some, the emerging research on culture and IS innovation questions mindless adoption. 
Studies in this area do not always explicitly state that they are contributing to the comprehension phase, such as studies dealing with IT fashion (Baskerville \& Myers, 2009; Wang, 2010a, 2010b). Some studies have explicitly tried to address aspects of comprehension by providing sensitizing frameworks (Lawrence \& Beltran, 2010) and methods of analyzing IT discourse though a cultural lens (Lawrence \& Rodriguez, 2012). However the existing research gives us sufficient theoretical knowledge to theorize the challenge of differentiation. IT innovators must thus possess contextually differentiated reasoning in order to select the appropriate IT for their organization (E. B. Swanson, 2010; E. B. Swanson \& Ramiller, 2004). Contextually differentiated reasoning directly addresses the issue of the "bandwagon phenomenon" (E. B. Swanson \& Ramiller, 2004; Walden \& Browne, 2009). The phenomenon exposes mimicry in IT adoption trends. Organizations will adopt technologies simply based on best practice or technology fashion (Baskerville \& Myers, 2009; Wang \& Ramiller, 2009). When innovators access IT community discourse, they are bombarded with rhetoric promoting the adoption of IT innovations. Thus, contextually differentiated reasoning gives the innovator the ability to identify if the use context fits with their organizational culture and goals. The challenge, thus, for innovators in our multi-cultural world is to also differentiate IT innovations based on culture.

These IT community discourses do not develop randomly, but are products of loosely coupled collaborations called organizing visions. Organizing visions are said to be comprised of inter-organizational communities of heterogeneous networks who have varying interests in a particular IT innovation, but who collectively create, and employ an organizing vision (B. Swanson \& Ramiller, 1997). Organizing visions are often grandiose and exaggerated beliefs of how IT should be applied. An organizing vision provides the functions of interpretation, legitimating, and mobilization. The aim is to provide a context of use of the IT innovation by giving social accounts of its potential applications. The next step is to legitimize the adoption of the innovation by linking the innovation with contemporary business issues, and with established and respected organizations, and people. Finally, organizing vision mobilizes market forces to develop and promote it throughout the community (Ramiller \& Swanson, 2003).

The process of comprehension is essentially a boundary-spanning process (E. B. Swanson \& Ramiller, 2004). Globalization has produced a multiplicity of boundaries due to greater interaction and specialization (Lindgren, Andersson, \& Henfridsson, 2008). Within boundaries, knowledge tends to be homogenous and stagnant (Kimble, Grenier, \& Goglio-Primard, 2010). Thus, to acquire knowledge of something that exists outside one's own organizational context, one must reach across organizational boundaries. Linking two or more groups separated by institutions, location, hierarchy, or function, facilitates boundary-spanning in organizational contexts (Kimble et al., 2010). 
Table 1. Cultural Challenges in IS Innovation Research

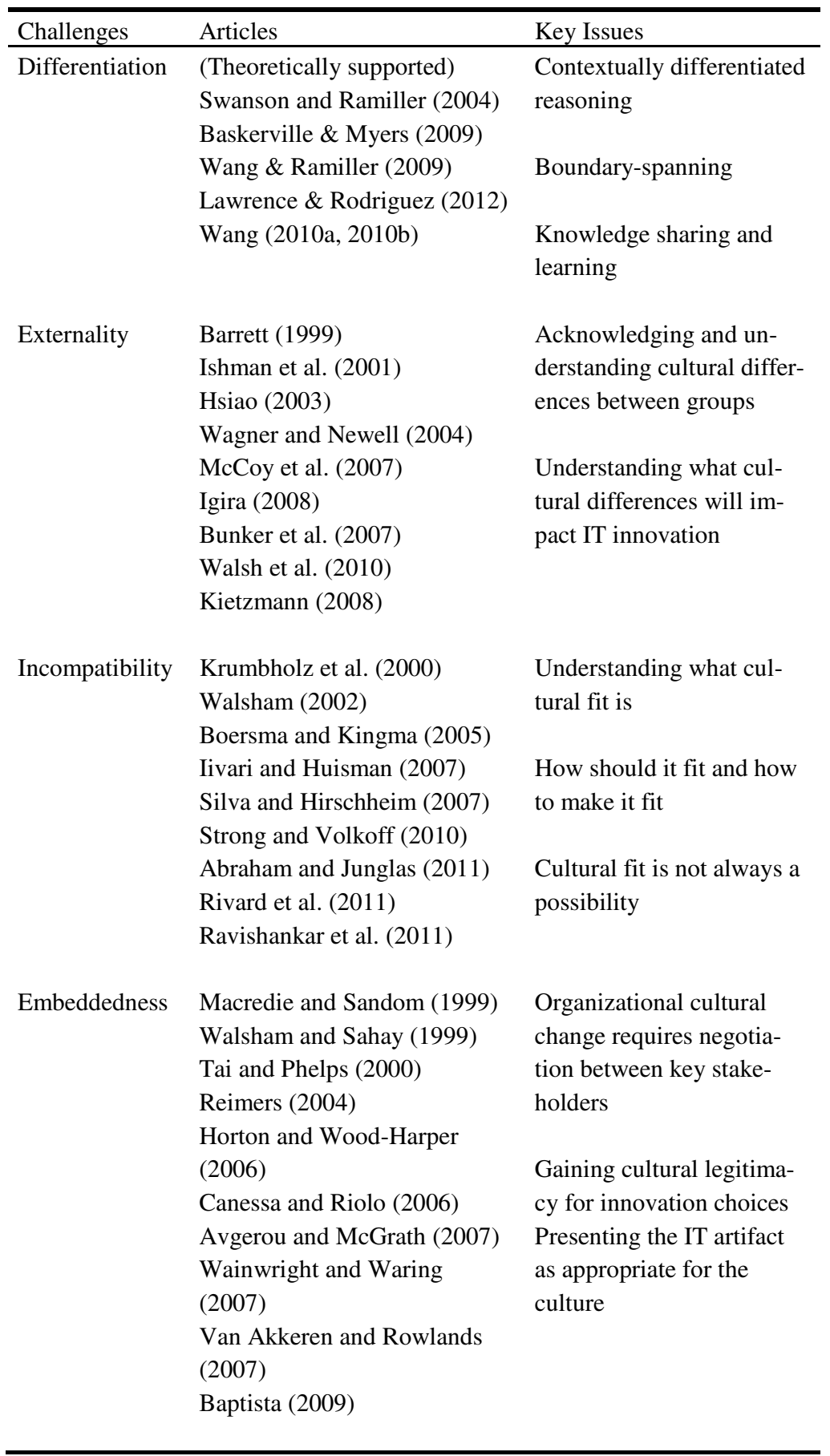




\subsection{Externality}

Introduction of external cultural elements including IT innovations have always been associated with change. Studies on this theme elaborate on the externality of IT artifacts, and the associated knowledge, and practices. The challenge is generally related to a lack of understanding and taken-for-granted assumptions about IT and culture. This theme involves research articles that stress differences in culture at national, organizational, and user levels.

Wagner and Newell's (2004) study investigated the issue of best practices in the IT industry. Their study revealed that organizations are made up of many endemic cultures, thus best practices presented by vendor organizations do not necessarily apply to adopting organizations and the endemic cultures that exist within them.

McCoy et al. (2007) warned against the underlying assumptions that IS theories developed and tested in a Western context would apply across cultures. In their study, they showed that applying TAM across cultures revealed inconsistent results. Contemporary conceptualizations of culture go beyond those of national and even organizational levels, thus understanding user-level cultural phenomena has also been investigated. In Kietzmann's (2008) study of two organizations collaborating to innovate with IT, she found that the two organizational contexts differed in their motivations to engage in the project. Without the development of an explicit shared vision, both organizations attempted to fulfill their own personal interests in the collaboration, leading to contradictions, and poor participation. Walsh et al. (2010) developed an IT user profile that would essentially be useful in identifying or creating customized applications for user groups within the organization. Their study was motivated by pre-packaged software adoption that is common practice in organizations. The externality of IT artifacts is emphasized in these studies because prior literature saw IT artifacts as neutral and not embedded with any cultural elements. These studies draw our attention to differences in cultural groups at different levels, and how their values, practices, and knowledge impact how we view and use IT. Barrett's (1999) longitudinal study found that cultural assumptions held by key stakeholders explained low levels of technology adoption in the organization. How managers view culture has a determining factor on what technology they chose to implement and how it is implemented.

Ingira's (2008) study sought to understand situated culture and its implications for IS innovation in a healthcare organization. Using activity theory, Igira provided an explanation of situated culture as activity systems representing user work practices. Culture itself was seen as embedded in activities that continuously transform over time with the introduction of new elements such as IT. The study drew attention to the persistence of cultural elements embedded in work practices. Any introduction of new elements into existing systems would create contradictions that would have to be resolved before value could be achieved. Hsiao's (2003) study further highlighted deep cultural issues such as values, fear, and trust. The study showed that cultural values related to how trust was achieved were embedded in external IT innovations. The study encouraged sensitivity to embedded cultural beliefs, as they would discourage technology use. 


\subsection{Incompatibility}

Incompatibility is the most practical explanation for conflict in IS innovation. Incompatibilities in cultural values, beliefs, practices, governance, etc. have been cited in articles included in this theme. This theme is dominated by articles that study the implementation phase of IS innovation, as innovators encounter cultural incompatibilities only when the IT innovations have already been adopted.

Silva and Hirschheim (2007) also saw that long-standing organizational cultures are embedded with structures that pose issues to IT implementation. The changes to organizational structure in order to implement IT innovations will face resistance. Of all the cultural elements deemed necessary for compatibility, values appear to be the most difficult to conceptualize, but have been found to cause the most cultural conflict. Krumbholz et al. (2000) saw that national culture minimally impacted the influence on IT implementation, but that incompatibility of core values based on organizational culture was a factor in the innovation process.

Misfits of culture and other organizational elements are a focal area that still has many challenges. Strong and Volkoff (2010) investigated technology fit in three organizations. They found that organizational culture fit was a key misfit domain. Ravishankar et al. (2011) tackled the issue of alignment in their study of a knowledgemanagement system implementation. They saw that the subculture level was a key element for technology alignment. When organizations understand the necessity of technology fit with subcultures in the organization, the innovation process is more successful. Similarly, Iivari and Huisman's (2007) study showed that a fit with organizational structure was an important technology fit dimension. Essentially, the cultural elements of IT through associated practices would compete with existing organizational practices when implemented. Thus, if organizational structures aligned to those of the IT innovation, a smoother transition could be made.

Boersman and Kingma's (2005) study indicates that transformation of the organization is often inevitable in large-scale IT implementations such as ERP, involving a transformation of both the organization, and the IT innovation. Their study showed that incompatibility is generally accepted and that transformation is necessary on both sides to achieve fit. Abraham and Junglas (2011) studied how the transformation of an organization with the implementations of IT can be positive. IT was not directly implicated in all the transformations but was seen as a catalyst. The resulting transformations, however, enabled easier implementation and assimilation. Macredie and Sandom's (1999) study showed that local improvisations were correlated to customer satisfaction during IT implementation. In cases where IT was adopted in a traditional hierarchical organization, local improvisations created improved implementation success. The study does, however, suggest that the IT innovation itself had to be adoptable.

Organizations need to change and organizational leadership is the orchestrator of change. In studies where there were apparent cultural differences (e.g.Walsham, 2002; Walsham \& Sahay, 1999) it was necessary to understand culture, but also leadership in cultural transformation. Particularly in cases of extreme cultural difference, technology fit and compatibility may be out of reach. Thus, organizational leaders 
must identify ways of reshaping their organizational cultures to take advantage of the necessary technological advancements essential for competitiveness. From this theme, the research shows that understanding cultural compatibility is key, but it may be impractical in many cases. Transformation of both the organization and its IT is thus essential to IS innovation success.

\subsection{Embeddedness}

For many organizations, a perfect fit is an illusion; thus, the agents charged with integrating IT into the organization's value chain are faced with the issue of conflict that is not only related to incompatibility, but also to unanticipated cultural resistance. Kai's (2004) study showed that while early adoption may prove successful, institutionalizing IT in cross-cultural settings reveals roadblocks related to culture. This theme addresses studies that go beyond implementation and look at the assimilation of IT into the organization. The sources of resistance and conflict in assimilation have to do with changing deeply embedded cultural elements.

Tai and Phelps (2000) studied chief executives' ability to overcome cultural resistance when innovating with IT. The study showed that the ability for chief executives to build a corporate culture to overcome resistance to technology was based on their perceptions of the IT vision, organizational IS issues, and IT support for knowledge management. The ability of senior leadership to understand the potential cultural challenges is key in mitigating cultural resistance. Canessa and Riolo (2006) studied how different implementations of computer-mediated communication would strengthen or dilute organizational culture, leading to differences in communication effectiveness. In their study, IT was shown to be able to have a direct impact on the resilience of culture over time. Keith and Harper (2006) conducted a longitudinal study of three police departments in the United Kingdom (UK). They concluded that the innovation process was a social activity involving constant social negotiations in the selection, implementation, and use of IT. Baptista (2009) studied the institutionalization of an intranet in a UK organization. The study found that the process of institutionalization is a product of ongoing negotiations of goals that present the IT artifact as the correct solution for the organization.

While improved productivity is generally the goal of IS innovation, embedded organizational culture has been shown to negate value due to a lack of assimilation. Avgerou and McGrath (2007) conducted a longitudinal study of IT innovation where power and authority over knowledge played a critical role in implementation failure, and where changes in governmental regimes continually changed the focus, and direction of IT in the organization. Wainwright and Waring (2007) studied how IT diffusion in organizations with strong professional cultures and ridged organizational controls posed problems for IT assimilation. Uprooting existing embedded organizational cultures is a challenge for innovators. Van Akkeren and Rowlands (2007) studied the assimilation of IT and its impact on organizational culture. The results showed that culture associated with IT through professional groups resulted in conflict. Professional groups such as those in the healthcare industry develop their own best practices. 


\subsection{Cultural Challenge Domino Effect}

Using a sample of the research on culture and IS innovation this paper conceptualized four cultural challenges that align with the four phases of IS innovation as defined by Swanson and Ramiller (2004). Shown in Table 2 the challenges not only show alignment but also reveal a domino effect. When these cultural challenges go unaddressed the negative effect ripples through the other phases. During comprehension the cultural challenge of differentiation requires organizations to use a cultural lens when making the adoption decision. This will allow them to understand cultural and contextual differences between their organizational and the IT's organizing vision. Not addressing this challenge would show cultural naivety from lack of learning about IT not just technically but socially.

Table 2. Cultural challenge waterfall

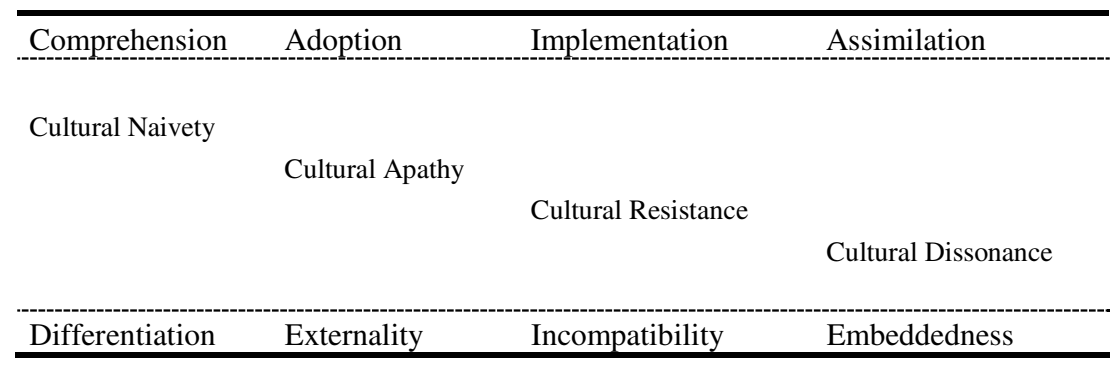

That naïve decision will be compounded when adoption occurs and the organization is challenged by the externality of the IT innovation. Cultural apathy at this stage ignores the externality of the IT innovation and results in cultural resistance during implemented due to the challenge of incompatibility. Continuing to ignore culture means that during assimilation the embedded culture never assimilates the IT innovation resulting in dissonance. Addressing these challenges in a timely manner by phase would provide a smoother innovation process in culturally challenging environments.

\section{The Differentiation Challenge: Opportunities for Research}

As we move to a more globally interconnected world, adoption of innovations without due consideration of the cultural contexts has been shown to be unwise. In the comprehension phase, the innovator must cross organizational boundaries to learn about the purpose, benefits, and technical features of an IT innovation in order to derive solutions, or identify opportunities. This type of learning is collaborative and rests on mutual understanding (B. Swanson \& Ramiller, 1997; Wang \& Ramiller, 2009). This paper proposes two opportunities for research to understand how we can mitigate the cultural challenge of differentiation in IS innovation. 


\subsection{Learning about IT across Cultural Boundaries}

Cultural differences embedded in organizational and national contexts are sometimes better understood at the micro-level. Walsham (2002) proposes micro-level analysis as a better way to understand cross-cultural working. At this level, one can reveal and learn more about cultural dynamics. Working to develop new technologies to appease everyone in cross-cultural settings is challenging, and issues ranging from different perspectives on needs, different work practices, and use of IT tools may arise in multicultural projects.

Within organizations, knowledge sharing occurs naturally through interaction, and organized formal and informal gatherings (Kimble et al., 2010). Knowledge sharing with the external environment is problematic often due to reluctance and contextual understanding. "Learning about" occurs during the comprehension and early adoption phases of innovation. It involves searching and exploring IT innovations. Learning about or learning without doing enables learning without actual engagement with the innovation (Wang \& Ramiller, 2009).

Ethnomethodological methods can be leveraged in this area as they have helped sociologists uncover taken-for-granted social norms and practices that are used in social interaction (See, Garfinkel, 1967, p 35). An offshoot of this approach used to investigate the specific context of talk-in-interaction is conversational analysis (L. Harvey \& M. D. Myers, 1995). Created by Harvey Sacks, conversational analysis provides us with a method particularly suited to studying interaction through discourse. This interaction is considered as institutional talk by conversational analysts-focus interaction enacted to achieve institutional objectives (Heritage \& Clayman, 2010). Conversational analysis exposes shared methods in interaction that can reveal successful and effective collaboration methods for comprehending IT innovations.

\subsection{Cultural Sense-Making of IT Innovations}

In the comprehension phase of IS innovation, boundary-spanning is also performed as a sense-making activity in order to perceive correctly peripheral information, internal or external to the organization (Lindgren et al., 2008; E. B. Swanson \& Ramiller, 2004). The goal of contextually differentiated reasoning, as in other complex negotiations of meaning, is achieving mutual agreement and shared understanding. Sensemakers use retrospective accounts to make sense of new phenomenon (Weick, 1995, p. 4). These accounts are derived from diverse members of collaborative groups. Sense-making is grounded in individual and group activity (Weick, 1995, p. 5). We could view organizing vision as the product of collective sense-making. Sensemaking is an iterative process, where individuals and groups form and reform assumptions and beliefs based on experiences.

As both a predecessor and successor activity to interpretation, sense-making involves the construction of the artifact to be interpreted, and translations of these interpretations into meaning (Weick, 1995, p. 8). Innovators seeking out IT innovations for adoption must interpret the discourses of IT in order to understanding its use context. It is thus through the awareness derived from previous experiences, either 
through the individual's, or group's experience, or that which has been learned through pervious sense-making activities, that the problem is framed. Comprehending an IT innovation that was designed and developed in an external context presents the challenge of using the innovator's previous experiences and background to make sense and derive the context of use of the innovation.

There are thus opportunities for deconstructing IS discourse though use of various discourse analysis methods to uncover cultural patterns. A common research method also shows potential when investigating comprehension. Content analysis is a research method for making inferences from text using a set of procedures. The study of text can reveal "cultural patterns of groups, institutions, or societies" (Weber 1980, p. 10). Krippendorff (2004) promotes the use of content analysis to expose social realities that "are too complex to be accessible otherwise." This method can be used to identify various cultural elements in symbolic systems that represent IT innovations. Content analysis, and other discourse methods, have been used to study IS innovation discourse at the field level (Tsui, Wang, Fleischmann, Oard, \& Sayeed, 2009).

\section{Conclusion}

In this paper we set out to better understand the cultural challenges facing innovators with IT in organizations. Through a synthesis of a sample of the literature, the paper revealed four cultural challenges correlating with IS innovation phase defined by Swanson and Remiller (2004). In the often ignore comprehension phase differentiation was theorized as the cultural challenge. In the adoption phase externality was the cultural challenge and during implementation we exposed that compatibility arose as the challenge for innovators and in the assimilation phase embeddeness was revealed as the cultural challenge. Additionally the study revealed that the challenges created a domino effect that would create and compound future challenges. The review also revealed that the comprehension phase where key adoption decisions are make was lacking in the research stream and provided opportunities for future research.

The study is limited by its conceptual nature but provides an important understanding and direction for research on IS innovation and culture. During comprehension organizations need to cross organizational and cultural boundaries to makes sense and learn about IT innovations. This requires knowledge to be put into context and greater understanding of cultural elements embedded in IT innovations. The paper draws attention to an under researched area of comprehension in IS innovation that is important for further investigation. The application of new and traditional research methods are recommended to investigate pre-adoption activities often ignored by IS innovation research.

\section{References}

Abraham, C., Junglas, I.: From cacophony to harmony: A case study about the IS implementation process as an opportunity for organizational transformation at Sentara Healthcare. The Journal of Strategic Information Systems 20(2), 177-197 (2011) 
Armstrong, C., Sambamurthy, V.: Information Technology Assimilation in Firms: The Influence of Senior Leadership and IT Infrastructures. Information Systems Research 10(4), 304-327 (1999)

Avgerou, C., McGrath, K.: Power, Rationality, and the Art of Living Through Socio-Technical Change. MIS Quarterly 31(2), 295-315 (2007)

Baptista, J.: Institutionalisation as a process of interplay between technology and its organizational context of use. Journal of Information Technology 24(4), 305-319 (2009)

Barrett, M., Jarvenpaa, S., Silva, L., Walsham, G.: ICTs, Globalization and Local Diversity. Communications of the Association for Information Systems 11(1), 486-497 (2003)

Barrett, M.I.: Challenges of EDI adoption for electronic trading in the London Insurance Market. European Journal of Information Systems 8(1), 1-15 (1999)

Baskerville, R., Myers, M.: Fashion on waves in information systems research and practice. MIS Quarterly 33(4), 647-662 (2009)

Boersma, K., Kingma, S.: From means to ends: The transformation of ERP in a manufacturing company. Journal of Strategic Information Systems 14(2), 197-219 (2005)

Canessa, E., Riolo, R.L.: An agent-based model of the impact of computer-mediated communication on organizational culture and performance: an example of the application of complex systems analysis tools to the study of CIS. Journal of Information Technology 21(4), 272 (2006)

Ein-Dor, P., Segev, E., Orgad, M.: The effect of national culture on IS: Implications for international information systems. Journal of Global Information Management 1(1), 33-44 (1993)

Fichman, R.: Going Beyond the Dominant Paradigm for Information Technology Innovation Research: Emerging Concepts and Methods. Journal of the Association for Information Systems 5(8), 314-355 (2004)

Garfinkel, H.: Studies in ethnomethodology. Blackwell Publishing Ltd., Malden MA (1967)

Hanseth, O., Braa, K.: Globalization and 'Risk Society'. In: Ciborra, C.U. (ed.) From Control to Drift, p. 3. Oxford University Press, Oxford (2000)

Harvey, L., Myers, M.D.: Scholarship and practice: the contribution of ethnographic research methods to bridging the gap. Information Technology \& People 8(3), 13-27 (1995)

Harvey, L., Myers, M.D.: Scholarship and practice: the contribution of ethnographic research methods to bridging the gap. Information Technology \& People 8(3), $13-27$ (1995)

Heritage, J., Clayman, S.: Dimensions of Institutional Talk. In: Talk in Action: Interactions, Identities and Institutions, pp. 34-50. Wiley-Blackwell, Oxford (2010)

Hofstede, G.: Cultures and Organizations: Software of the Mind. McGraw-Hill (2004)

Hsiao, R.-L.: Technology Fears: Distrust and Cultural Persistence in Electronic Marketplace Adoption. The Journal of Strategic Information Systems (12), 169-199 (2003)

Igira, F.T.: The situatedness of work practices and organizational culture: implications for information systems innovation uptake. Journal of Information Technology 23(2), 79 (2008)

Iivari, J., Huisman, M.: The Rellationship between Organizational Culture and the Deployment of Systems Development Methodologies. MIS Quarterly 31(1), 35 (2007)

Kai, R.: GEARBOX (China) Ltd.: will the company's ERP system support its ambitious growth strategy? Journal of Information Technology 19(2), 140 (2004)

Kaptelinin, V., Nardi, B.: Artifacts, Agents, and (A)symmetry. In: Acting with Technology Activity Theory and Interaction Design, pp. 237-252, 210. MIT Press (2006)

Karahanna, E., Straub, D.W., Chervany, N.: Information Technology Adoption across Time: A Cross-Sectional Comparison of Pre-Adoption and Post-Adoption Beliefs. MIS Quarterly 23(2), 183-213 (1999) 
Kaye, R., Little, S.: Global business and cross-cultural information systems: Technical and institutional dimensions of diffusion. Information Technology \& People 9(3), 30-54 (1996)

Keith, S.H., Trevor, A.W.-H.: The shaping of I.T. trajectories: evidence from the U.K. public sector. European Journal of Information Systems 15(2), 214 (2006)

Kietzmann, J.: Interactive innovation of technology for mobile work. European Journal of Information Systems 2008(3), 305-320 (2008)

Kim, S., Malhotra, N.K.: A longitudinal model of continued IS use: an integrative view of four mechanisms underlying post-adoption phenomena. Management Science 51(5), 741-755 (2005)

Kimble, C., Grenier, C., Goglio-Primard, K.: Innovation and knowledge sharing across professional boundaries: Political interplay between boundary objects and brookers. International Journal of Information Management 30, 437-444 (2010)

King, J.L., Gurbaxani, V., Kraemer, K.L., McFarlan, W.F., Raman, K.S., Yap, C.S.: Institutional Factors in Information Technology Innovation. Information Systems Research 5(2), 139-169 (1994)

Krippendorff, K.: Content Analysis: An Introduction to its Methodology, 2nd edn. Sage, Thousand Oaks (2004)

Krumbholz, M., Galliers, J., Coulianos, N., Maiden, N.A.M.: Implementing enterprise resource planning packages in different corporate and national cultures. Journal of Information Technology 15(4), 267 (2000)

Lawrence, C.A., Beltran, F.: Caveat Emptor: Cultural Assumptions in Information Technology Innovation. Paper Presented at the Proceeding of the 16th Americas Conference on Information Systems, AMCIS 2010 (2010)

Lawrence, C.A., Rodriguez, P.: The Interpretation and Legitimization of Values in Agile's Organizing Vision. Paper Presented at the Proceedings of the European Conference on Information Systems, ECIS 2012 (2000/2012)

Leidner, D.E.: Globalization, culture, and information: Towards global knowledge transparency. The Journal of Strategic Information Systems 19(2), 69-77 (2010), doi:10.1016/j.jsis.2010.02.006

Lindgren, R., Andersson, M., Henfridsson, O.: Multi-contextuality in Boundary-Spanning practices. Information Systems Journal 18, 641 (2008)

Lucas, H.C.J., Swanson, E.B., Zmud, R.: Implementation, Innovation, and Related Themes Over The Years In Information Systems Research. Journal of the Association for Information Systems 8(4), 205-211 (2007)

Macredie, R.D., Sandom, C.: IT-enabled change: Evaluating an improvisational perspective. European Journal of Information Systems 8(4), 247 (1999)

Mustonen-Ollila, E., Lyytinen, K.: How organizations adopt information system process innovations: a longitudinal analysis. European Journal of Information Systems 13(1), 35-51 (2004)

Myers, M., Tan, F.: Beyond models of national culture in information systems research, 14-29 (2003) doi:citeulike-article-id:3752890

Orlikowski, W.J., Gash, D.C.: Technological frames: making sense of information technology in organizations. ACM Trans. Inf. Syst. 12(2), 174-207 (1994), doi:10.1145/196734.196745

Pinch, T.: Technology and institutions: living in a material world. Theory and Society 37(5), 461-483 (2008) doi:citeulike-article-id:3440325

Pinch, T., Bijker, W.: The Social Construction of Facts and Artefacts: or How the Sociology of Science and the Sociology of Technology might Benefit Each Other. Social Studies of Science 14(3), 399-441 (1984) doi:citeulike-article-id:3997929 
Ramiller, N., Swanson, B.: Organizing Visions for Information Technology and the I.S. Executive Response. Journal of Management Information Systems 20(1), 13-50 (2003)

Rau, S.E., Bye, B.S.: ARE YOU GETTING VALUE FROM YOUR IT? Journal of Business Strategy 16, 15 (2003)

Ravishankar, M., Pan, S., Leidner, D.: Examining the Strategic Alignment and Implementation Success of a KMS: A Subculture-Based Multilevel Analysis. Information Systems Research 22, 39 (2011)

Scott, M., Dennis, F.G., William, R.K.: Applying TAM across cultures: the need for caution. European Journal of Information Systems 16(1), 81 (2007)

Silva, L., Hirschheim, R.: Fighting Against Windmills: Strategic Information Systems and Organizational Deep Structures. MIS Quarterly 31(2), 327-354 (2007)

Strong, D., Volkoff, O.: Understanding Organization-Enterprise System Fit: A Path to Theorizing the Information Technology Artifact. MIS Quarterly 34(4), 731 (2010)

Swanson, B.: Information systems innovation among organizations. Management Science 40(9), 1069-1092 (1994)

Swanson, B., Ramiller, N.: The Organizing Vision in Information Systems Innovation. Organization Science 8(5), 458-474 (1997)

Swanson, E.B.: Consultancies and capabilities in innovating with IT. Journal of Strategic Information Systems 19(1), 17-27 (2010)

Swanson, E.B., Ramiller, N.C.: Innovating mindfully with information technology. MIS Quarterly: Management Information Systems 28(4), 553-583 (2004)

Tai, L.A., Phelps, R.: CEO and CIO perceptions of information systems strategy: Evidence from Hong Kong. European Journal of Information Systems 9(3), 163 (2000)

Tsui, C.-J., Wang, P., Fleischmann, K.R., Oard, D.W., Sayeed, A.B.: Understanding IT Innovations Through Computational Analysis of Discourse. In: Paper Presented at the International Conference on Information Systems (2009)

Van Akkeren, J., Rowlands, B.: An epidemic of pain in an Australian radiology practice. European Journal of Information Systems 16(6), 695 (2007)

Vasst, E., Walsham, G.: Representations and Actions: the transformation of work practices with IT use. Information and Organization 2005(15), 65-89 (2005)

Vodanovich, S., Sundaram, D., Myers, M.: Digital Natives and Ubiquitous Information Systems. Information Systems Research 21(4), 711-723 (2010)

Wagner, E.L., Newell, S.: 'Best' for whom?: the tension between 'best practice' ERP packages and diverse epistemic cultures in a university context. The Journal of Strategic Information Systems 13(4), 305-328 (2004), doi:10.1016/j.jsis.2004.11.002

Wainwright, D.W., Waring, T.S.: The application and adaptation of a diffusion of innovation framework for information systems research in NHS general medical practice. Journal of Information Technology 22(1), 44 (2007)

Walden, E., Browne, G.: Sequential Adoption Theory: A Theory for Understanding Herding Behavior in Early doption of Novel Technologies. Journal of the Association for Information Systems 10(1), 31-62 (2009)

Walsh, I., Kefi, H., Baskerville, R.: Managing culture creep: Toward a strategic model of user IT culture. The Journal of Strategic Information Systems 19(4), 257-280 (2010), doi:10.1016/j.jsis.2010.09.002

Walsham, G.: Cross-Cultural Software Production and Use: A Structurational Analysis. MIS Quarterly 26(4), 359-380 (2002) 
Walsham, G., Sahay, S.: GIS for District-Level Administration in India: Problems and Opportunities. MIS Quarterly 23(1), 39-66 (1999)

Wang, P.: Chasing the Hottest IT: Effects of Information Technology Fashion on Organizations. MIS Quarterly 34(1), 65-85 (2010a)

Wang, P.: The Surprising Impact of Fashions in Information Technology. Sloan Management Review 51(4), 14-17 (2010b)

Wang, P., Ramiller, N.C.: Community Learning in Information Technology Innovation. MIS Quarterly 33(4), 709 (2009)

Weick, K.E.: Sensemaking in Organizations. Sage, Thousand Oaks (1995) 